\title{
Treatment for obstructive sleep apnoea: effect on peripheral nerve function
}

\section{Rainer Dziewas, Matthias Schilling, Philipp Engel, Matthias Boentert, Hyon Hor, Angelika Okegwo, Peter Lüdemann, E Bernd Ringelstein, Peter Young}

See Editorial Commentary, p 222

J Neurol Neurosurg Psychiatry 2007;78:295-297. doi: 10.1136/jnnp.2006.102806

See end of article for authors' affiliations

......................

Correspondence to:

Dr Rainer Dziewas,

Department of Neurology, University Hospital of

Münster, Albert-Schweitzer-

Strasse 33, 48129 Münster

Germany; dziewas

@uni-muenster.de

Received 20 July 2006

Revised 15 September 2006

Accepted

19 September 2006

Published Online First

29 September 2006
Background and objective: Obstructive sleep apnoea (OSA) is suggested to be associated with peripheral nerve damage. A case-control study was conducted to provide further support to this observation. In a longitudinal intervention study, it was examined whether treatment for OSA has a possible beneficial effect on peripheral nerve function.

Methods: Participants were 23 patients with OSA and 23 controls matched for age and body mass index (BMI), all without any known cause of peripheral nerve damage. The sensory nerve action potential (SNAP) amplitudes of both sural nerves were determined. After 6 months of treatment for OSA, treatment compliance was evaluated and nerve conduction studies were repeated.

Results: Patients with OSA had significantly lower mean (standard deviation) sural SNAP amplitudes than controls (6.3 (3.5) v $11.2(5.0), p<0.001)$. Multivariate regression analysis including the variables age, $\mathrm{BMI}$ and Apnoea-Hypopnea Index (AHI) showed that both age $(p<0.01)$ and $A H I(p<0.05)$ were inversely related to the SNAP amplitude. On follow-up, the sural SNAP showed an increase of $2.6 \mathrm{mV}$ on average $(p<0.001)$. Multivariate regression analysis including the variables age, BMI, AHI, pretreatment SNAP and treatment compliance identified only treatment compliance as being significantly related to the SNAP increase $(p \leqslant 0.005)$

Conclusion: OSA is an independent risk factor for axonal dysfunction of peripheral sensory nerves. Impaired neural function is at least partly reversible with treatment for sleep apnoea.
$\mathrm{O}$ bstructive sleep apnoea (OSA) is a common disorder with an estimated prevalence in the general population of 2-5\%. ${ }^{1}$ Its main clinical features are loud snoring and breathing stoppage during sleep. Owing to non-restful sleep, patients with OSA experience excessive daytime sleepiness and related neuropsychological impairments. ${ }^{2}$ By different pathophysiological mechanisms, OSA is known to be associated with arterial hypertension, ${ }^{3}$ a hypercoagulable state, ${ }^{4}$ decreased cerebral perfusion, ${ }^{5}$ arteriosclerosis ${ }^{6}$ and severe cardiac arrhythmias, $^{7}$ all of which potentially contribute to the increased mortality and cerebrocardiovascular morbidity of patients with OSA. $^{8} 9$

Apart from that, an association of OSA with damage to the peripheral nervous system has been described only recently. ${ }^{10} 11$ Thus, we reported an increased prevalence of axonal sensory polyneuropathy in patients with OSA. ${ }^{11}$ This study found a decreased sural sensory nerve action potential (SNAP) in patients with OSA compared with controls. Additionally, a correlation of axonal dysfunction with the extent of oxygen desaturation was observed. We hypothesised that intermittent hypoxaemia is an independent risk factor for axonal dysfunction of peripheral nerves. ${ }^{11}$

This study had two aims: (1) to replicate our previous results in another case-control study, thereby providing further support to the assumed pathophysiology; and (2) to examine a possible, beneficial effect of treatment for OSA on peripheral nerve function in a longitudinal intervention study.

\section{PATIENTS AND METHODS}

\section{Patients}

We included 23 patients with newly diagnosed OSA in the study. In each case, OSA was diagnosed by polysomnography (overnight recording of sleep-wake cycles, electrocardiogram, electroencephalogram, electromyogram, anterior tibialis electromyogram, oronasal air flow, chest wall and abdominal wall effort, and pulse oximetry). ${ }^{12}$ All individuals with OSA had an Apnoea-Hypopnea Index (AHI) of $>10$. Apart from the AHI, the percentage of night time with oxygen saturation below $90 \%\left(\mathrm{CT}_{90}\right)$ was determined.

\section{Controls}

Controls $(n=23)$ were admitted to hospital for suspected OSA that was not confirmed by polysomnography (17 were diagnosed with uncomplicated snoring, 4 with periodic limb movements and 3 with poor sleep hygiene). All controls had AHI $<5$. Controls were matched for age and BMI to the patients with OSA.

Patients with OSA and controls with a known cause of polyneuropathy such as diabetes mellitus, alcoholism, renal failure, carcinoma, disorders of immune-mediated injury and use of neurotoxic drugs were excluded from the study. In all participants, levels of fasting glucose, haemoglobin $\mathrm{A}_{\mathrm{IC}}$ creatinine and hepatic enzymes were within the normal laboratory range. No patient had baseline hypoxia.

Nerve conduction studies were performed on a Keypoint electroneurographical system (Dantec, Skovlunde, Denmark) using standard techniques as described previously. ${ }^{13}$ Skin temperature was maintained at $34^{\circ} \mathrm{C}$ during measurement. The base to peak amplitude of SNAP of both sural nerves was determined. For further analysis, the SNAP amplitudes were averaged. The investigator was blinded to the result of the sleep study.

Abbreviations: AHI, Apnoea-Hypopnea Index; BMI, body mass index; $\mathrm{CT}_{90}$, percentage of night time with an oxygen saturation below $90 \%$; nCPAP, nasal continuous airway pressure; OSA, obstructive sleep apnoea; $\mathrm{RICF}$, resistance to ischaemic conduction failure; SNAP, sensory nerve action potential 
Table 1 Characteristics of controls and patients with obstructive sleep apnoea

\begin{tabular}{|c|c|c|c|c|}
\hline & $\begin{array}{l}\text { Controls } \\
n=23^{*}\end{array}$ & $\begin{array}{l}\text { With OSA } \\
n=23^{*}\end{array}$ & t Value & p Value \\
\hline Age (years) & $51.1(12.2)$ & $54.8(11.1)$ & -1.07 & 0.29 \\
\hline $\mathrm{BMI}\left(\mathrm{kg} / \mathrm{m}^{2}\right)$ & $28.8(5.0)$ & $31.6(4.9)$ & -1.87 & 0.067 \\
\hline $\mathrm{AHI}$ & $2.7(2.4)$ & 34.7 (23.2) & -6.58 & $<0.001$ \\
\hline $\mathrm{CT}_{90}$ & $2.9(2.5)$ & 27.9 (12.2) & -9.63 & $<0.001$ \\
\hline SNAP $(\mu \mathrm{V})$ & $11.2(5.0)$ & $6.3(3.5)$ & 3.87 & $<0.001$ \\
\hline $\mathrm{AHI}_{\mathrm{Th}}$ & NA & $3.7(2.4)$ & NA & NA \\
\hline $\mathrm{CT}_{90 \mathrm{Th}}$ & NA & $2.0(1.3)$ & NA & NA \\
\hline Compl (\%) & NA & $82.9(23.7)$ & NA & NA \\
\hline
\end{tabular}

$\mathrm{AHI}$, Apnoea-Hypopnoea Index; $\mathrm{AH}_{\mathrm{Th}}, \mathrm{AHI}$ with sleep apnoea therapy; $\mathrm{BMI}$, body mass index; Compl, treatment compliance; $\mathrm{CT}_{90}$, percentage of night time with oxygen saturation below $90 \% ; \mathrm{CT}_{90 \mathrm{Th}}, \mathrm{CT}_{90}$ with sleep apnoea therapy; NA, not applicable; SNAP, sensory nerve action potential. *Values are mean (SD).

\section{Treatment and follow-up examination}

Eighteen patients with OSA were treated with nasal continuous airway pressure (nCPAP). Five patients were diagnosed with positional OSA and received treatment with a backpack for preventing them from sleeping in the supine position. After 6 months, a second nerve conduction study was performed. Data on treatment compliance were provided by the nCPAP devices (percentage of days used and hours per night used). Patients receiving positional treatment had been asked to record their daily usage during the study time.

\section{Statistical analysis}

For statistical analysis, STATISTICA for Windows version 4 was used. Univariate comparisons were carried out with the t test for paired and unpaired data, as appropriate. Multivariate regression analysis was performed to identify variables correlated with the pretreatment SNAP amplitude and to assess parameters associated with an increase in the SNAP amplitude on follow-up.

\section{RESULTS}

Patients with OSA and controls were well matched for age. Patients were more obese than controls, although this difference did not reach significance. As expected, patients had on average a more than tenfold higher AHI than controls. A similar difference was found for $\mathrm{CT}_{90}$. As expected, we found a highly significant correlation of $\mathrm{AHI}$ and $\mathrm{CT}_{90}$ across all participants (Spearman's $\mathrm{R}=0.96, \mathrm{p}<0.001$ ). Nerve conduction studies showed a significant difference in the mean sural SNAP

Table 2 Results of multivariate regression analysis

\begin{tabular}{|c|c|c|c|c|}
\hline & $\beta$ & SE of $\beta$ & t Value & p Value \\
\hline \multicolumn{5}{|c|}{ A. Parameters correlating with the initial sural SNAP } \\
\hline $\mathrm{BMI}$ & -0.15 & 0.15 & -0.96 & 0.34 \\
\hline $\mathrm{AHI}$ & -0.33 & 0.15 & -2.19 & 0.034 \\
\hline Age & -0.44 & 0.13 & -3.46 & 0.001 \\
\hline \multicolumn{5}{|c|}{$\begin{array}{l}\text { B. Parameters correlating with the difference between the second and the } \\
\text { first sural SNAP }\end{array}$} \\
\hline $\mathrm{BMI}$ & 0.09 & 0.25 & 0.13 & 0.72 \\
\hline $\mathrm{AHI}$ & -0.37 & 0.20 & 0.37 & 0.085 \\
\hline Age & -0.43 & 0.24 & -1.83 & 0.087 \\
\hline SNAP & 0.25 & 0.18 & -1.82 & 0.17 \\
\hline Compl & 0.56 & 0.17 & 3.25 & 0.005 \\
\hline
\end{tabular}

AHI, Apnoea-Hypopnea Index; $\beta$, partial correlation coefficient; BMI, body mass index; Compl, treatment compliance; SNAP, pretreatment sensory nerve action potential. amplitudes between both groups, with patients with OSA having significantly lower amplitudes than controls (table 1).

Multivariate regression analysis taking into account all 46 participants and including the variables age, BMI and AHI showed that both age $(\mathrm{p}<0.01)$ and AHI $(\mathrm{p}<0.05)$ were inversely related to the SNAP amplitude (table $2 \mathrm{~A}$ ).

In all patients with OSA, treatment led to a normalisation of the AHI. With a relative usage of nearly $83 \%$ of all nights, treatment compliance was generally good. However, there was a high interindividual variability as shown by a range of 10 $100 \%$. Although 14 patients used the device more than $90 \%$ of all nights, 9 patients had a usage below $90 \%$ and 5 of these showed a poor compliance of below 70\%.

Patients with OSA with good and moderate or bad compliance did not differ with regard to basic epidemiological and sleep parameters (table 3). Overall, on follow-up, the sural SNAP showed on average an increase of $2.6 \mu \mathrm{V}$, which was highly significant (table 3 ). This effect was mainly due to the SNAP increase found in the high-compliance group, whereas patients with a moderate or poor compliance showed only a minimal improvement in SNAP amplitudes. In line with univariate statistics, multivariate regression analysis including the variables age, BMI, AHI, pre-treatment SNAP and treatment compliance identified only treatment compliance as being significantly related to the SNAP increase (table $2 \mathrm{~B}$ ).

\section{DISCUSSION}

With the first part of our study, we confirmed our previous results. ${ }^{11}$ Thus, in patients with OSA, the sural SNAP amplitude was nearly $5 \mu \mathrm{V}$ less than that in controls, a difference that was also found in the previous investigation. Multivariate regression analysis including all participants further showed that the amplitude of the sural SNAP was inversely related to the AHI and to age. Therefore, apart from increasing age, which has long been known to be associated with peripheral nerve dysfunction, ${ }^{14}$ sleep apnoea may constitute an additional independent risk factor for predominantly axonal sensory nerve damage. As, in the same analysis, the BMI showed no correlation with the sural SNAP, the difference between patients with OSA and controls is not attributable to an increased subcutaneous fat in the OSA group. As a limitation to these findings, we have to admit that other conditions associated with peripheral nerve damage, such as peripheral vascular disease, impaired thyroid function and decreased

Table 3 Comparison of patients with obstructive sleep apnoea with good $(\geqslant 90 \%)$ and moderate to bad compliance (<90\%)

\begin{tabular}{lllll}
\hline & $\begin{array}{l}\text { Usage } \geqslant 90 \% \\
\mathbf{n}=\mathbf{1 4}\end{array}$ & $\begin{array}{l}\text { Usage }<\mathbf{9 0 \%} \\
\mathbf{n}=\mathbf{9}\end{array}$ & $\begin{array}{l}\text { All patients } \\
\mathbf{n = 2 3}\end{array}$ & $\mathbf{p}$ Value \\
\hline Age (years) & $53.9(12.9)$ & $56.3(9.7)$ & $54.8(11.1)$ & $\mathrm{NS}$ \\
$\mathrm{BMI}\left(\mathrm{kg} / \mathrm{m}^{2}\right)$ & $32.4(5.5)$ & $30.3(3.8)$ & $31.6(4.9)$ & $\mathrm{NS}$ \\
$\mathrm{AHI}$ & $35.4(23.3)$ & $33.6(24.3)$ & $34.7(23.2)$ & $\mathrm{NS}$ \\
$\mathrm{AHI}$ & $3.2(2.5)$ & $4.4(2.2)$ & $3.7(2.4)$ & $\mathrm{NS}$ \\
Usage $(\%)$ & $95.8(3.6)$ & $62.7(27.8)$ & $82.9(23.7)<0.001$ \\
SNAP $(\mu \mathrm{V})$ & & & & \\
$\quad \begin{array}{l}\text { Pretreatment } \\
\text { Post-treatment }\end{array}$ & $5.9(4.1)$ & $6.8(2.7)$ & $6.3(3.6)$ & $\mathrm{NS}$ \\
$\quad \begin{array}{l}\text { Difference } \\
\quad \text { Paired }\end{array}$ & $4.9(6.4)$ & $7.2(3.0)$ & $8.9(5.2)$ & $\mathrm{NS}$ \\
comparison & $\mathrm{p}<0.001$ & $0.4(1.5)$ & $2.6(3.1)$ & $<0.01$ \\
& & $\mathrm{NS}$ & $\mathrm{p}<0.001$ & \\
\hline
\end{tabular}

AHI, Apnoea-Hypopnoea Index; $\mathrm{AHI}_{\mathrm{Th}}, \mathrm{AHI}$ with sleep apnoea therapy; BMI, Body Mass Index; SNAP, sensory nerve action potential. Paired comparison refers to a comparison of pretreatment and posttreatment SNAP amplitudes within each compliance group.

Values in parentheses are SD. 
levels of vitamin $\mathrm{B}_{12}$ and folic acid, have not been systematically studied here and may therefore bias our results.

The second part of our study further corroborated the previous results by finding a considerable increase in the sural SNAP amplitude 6 months after initiation of OSA treatment. As shown by multivariate regression analysis, treatment compliance was the only variable significantly associated with improved neural function. We may therefore assume that neural dysfunction is at least partly reversible with treatment in patients with OSA. Interestingly, the extent of pre-existing nerve damage had no effect on the subsequent treatment effect, suggesting that despite exposure to intermittent hypoxaemia possibly lasting several years, pathophysiological changes are partly functional rather than structural.

To the best of our knowledge, only one study has examined the effect of nCPAP treatment on peripheral nerve function in a small collection of patients with OSA. Mayer et $a l^{10}$ used the resistance to ischaemic conduction failure (RICF) as a neurophysiological marker of peripheral nerve dysfunction. ${ }^{10}$ RICF is characterised by abnormal persisting nerve conduction during ischaemia and is one of the earliest abnormalities of peripheral nerve function in various metabolic conditions such as diabetes, chronic hypoxia and chronic renal failure. ${ }^{15-17}$ The authors found RICF in 7 of 17 patients with OSA and in none of the controls. After 2 months of nCPAP treatment, four patients with OSA with RICF were re-evaluated. In all of them this neurophysiological abnormality had disappeared, whereas preischaemic nerve conduction parameters were unchanged and suggested persisting axonal dysfunction.

\section{CONCLUSION}

Just like chronic hypoxaemia caused by chronic obstructive pulmonary disease, ${ }^{18}{ }^{19}$ recurrent intermittent hyoxaemia may be an independent risk factor for peripheral sensory nerve dysfunction. Secondly, comparable to the effect observed in other OSA-related disorders such as hypertension, ${ }^{20}$ thrombophilia $^{21}$ and cardiac rhythm disturbances, ${ }^{7}$ treatment for OSA might also result in improved function of peripheral nerves.

\section{Authors' affiliations \\ Rainer Dziewas, Matthias Schilling, Philipp Engel, Matthias Boentert, Hyon Hor, Angelika Okegwo, Peter Lüdemann, E Bernd Ringelstein, Peter Young, Department of Neurology, University Hospital of Münster, Münster, Germany}

Funding: This study was supported by Innovative Medizinische Forschung (IMF DZ 120140).
Competing interests: None declared.

\section{REFERENCES}

1 Young T, Palta M, Dempsey J, et al. The occurrence of sleep-disordered breathing among middle-aged adults. N Engl J Med 1993;328:1230-5.

2 Naegele B, Thouvard V, Pépin JL, et al. Deficits of cognitive executive functions in patients with sleep apnea syndrome. Sleep 1995;18:43-52.

3 Peppard PE, Young T, Palta M, et al. Prospective study of the association between sleep-disordered breathing and hypertension. N Engl J Med 2000;342:378-84.

4 Robinson GV, Pepperell JCT, Segal HC, et al. Circulating cardiovascular risk factors in obstructive sleep apnoea: data from randomised controlled trials. Thorax 2004;59:777-82.

5 Diomedi M, Placidi F, Cupini LM, et al. Cerebral hemodynamic changes in sleep apnea syndrome and effect of continuous positive airway pressure treatment. Neurology 1998;51:1051-6.

6 Sivestrini M, Rizzato B, Placidi F, et al. Carotid artery wall thickness in patients with obstructive sleep apnea syndrome. Stroke 2002;33:1782-5.

7 Harbison JA, O'Reilly P, McNicholas WT. Cardiac rhythm disturbances in the obstructive sleep apnea syndrome: effects of nasal continuous positive airway pressure therapy. Chest 2000;1 18:591-5.

$8 \mathrm{He} \mathrm{J}$, Kryger MH, Zorich FJ, et al. Mortality and apnea index in obstructive sleep apnea: experience in 385 male patients. Chest 1988;94:9-14.

9 Shahar E, Whitney CW, Redline S, et al. Sleep-disordered breathing and cardiovascular disease. Am J Respir Crit Care Med 2001;163:19-25.

10 Mayer P, Dematteis M, Pépin JL, et al. Peripheral neuropathy in sleep apnea. A tissue marker of the severity of nocturnal desaturation. Am J Respir Crit Care Med $1999 ; 159: 213-19$.

11 Lüdemann P, Dziewas R, Sörös P, et al. Axonal polyneuropathy in obstructive sleep apnoea. J Neurol Neurosurg Psychiatry 2001;70:685-7.

12 Rechtschaffen A, Kales A. A manual of standardized terminology, techniques and scoring system for sleep stages in human subjects. Washington, DC: National Institute of Neurological Disease and Blindness, 1968.

13 Reinhardt F, Wetzel T, Vetten S, et al. Peripheral neuropathy in chronic venous insufficiency. Muscle Nerve 2000;23:883-7.

14 Izzo KL, Aravabbumi S, Jafri A, et al. Medial and lateral antebrachial cutaneous nerves: standardization of technique, reliability and age effect on healthy subjects. Arch Phys Med Rehabil 1985;66:592-7.

15 Horowitz SH, Ginsberg-Fellner F. Ischemia and sensory nerve conduction in diabetes mellitus. Neurology 1979;29:695-704.

16 Hampton KK, Alani SM, Wison Jl, et al. Resistance to ischemic conduction failure in chronic hypoxemia and diabetes. I Neurol Neurosurg Psychiatry 1989;52:1303-5.

17 Castaigne P, Cathala HP, Beaussart-Boulengé L, et al. Effect of ischemia on peripheral nerve function in patients with chronic renal failure undergoing dialysis treatment. J Neurol Neurosurg Psychiatry 1972;35:631-4.

18 Pfeiffer G, Kunze K, Brüch M, et al. Polyneuropathy associated with chronic hypoxemia: prevalence in patients with chronic obstructive pulmonary disease. J Neurol 1990;237:230-3.

19 Pozza JJ, Marti-Masso JF. Peripheral neuropathy associated with chronic obstructive pulmonary disease. Neurologia 1997;12:389-94.

20 Becker HF, Jerrentrup A, Ploch T, et al. Effect of nasal continuous positive airway pressure treatment on blood pressure in patients with obstructive sleep apnea. Circulation 2003; 107:68-73.

21 Bobinsky G, Miller M, Ault K, et al. Spontaneous platelet activation and aggregation during obstructive sleep apnea and its response to therapy. Chest $1995 ; 108: 625-30$. 